EESTI NSV TEADUSTE AKADEEMIA TOIMETISED. XIV KÖIDE

FOOSIKA-MATEMAATIKA- JA TEHNIKATEADUSTE SEERIA. 1965, NR. 2

ИЗВЕСТИЯ АКАДЕМИИ НАУК ЭСТОНСКОИ ССР. ТОМ ХІV

СЕРИЯ ФИЗИКО-МАТЕМАТИЧЕСКИХ И ТЕХНИЧЕСКИХ НАУК. 1965, № 2

И. КЛЕСМЕНТ, Э. ЛАГЕДА

\title{
ИДЕНТИФИКАЦИЯ ФЕНОЛОВ В ГАЗОХРОМАТОГРАФИЧЕСКИХ ФРАКЦИЯХ КАТАЛИТИЧЕСКИМ ДЕГИДРИРОВАНИЕМ
}

Для анализа сложных фенольных смесей нами был разработан метод дегидроксилирования фенолов в ароматические углеводороды [1]. Согласно этому методу фенолы дегидроксилируют в микрореакторе на $\mathrm{Pd}$-катализаторе $(5 \%$ от веса носителя диатомита) в токе водорода при $330-340^{\circ} \mathrm{C}$, катализат конденсируют и его состав определяют газохроматографически. Метод дает возможность быстро определить структуры углеводородных скелетов фенолов и других кислородных соединений. При этом, однако, он имеет ряд недостатков. Для получения более подробных данных необходимо предварительно разделить фенолы, получить их газохроматографическую характеристику и дегидроксилировать все компоненты отдельно. Этот способ позволяет также определить отдельно продукты деалкилирования каждого фенольного компонента.

Для усовершенствования метода [1] были изучены два варианта:

1. Фенолы $(250-500$ мкл) разделяют на полупрепаративной газохроматографической колонке, конденсируют и состав каждого компонента определяют отдельно по методу ['].

2. Фенолы разделяют на обычной аналитической колонке и дегидроксилируют в микрореакторе, поставленном за колонкой. Пары катализата проходят детектор, и продукты реакции каждого пика конденсируют отдельно. Состав каждой фракции катализата определяется на хроматографе, снабженном ионизационным детектором.

Для успешного решения поставленной задачи необходимо возможно более четкое предварительное разделение фенолов. Фенолы как высокополярные и высококипящие соединения трудно подвергаются газохроматографическому разделению. Для их анализа используются как полярные (сахары [2], трикрезилфосфат [ $\left.{ }^{3}\right]$ ), так и неполярные (силиконовые масла [4], апиезоны [5], ланолин [6]) неподвижные фазы.

Последовательность выхода из колонки близкокипящих групп фенолов зависит от полярности неподвижной фазы. Из полярных колонок выходят первыми одноатомные, из неполярных - двухатомные фенолы. Полярные фазы термически менее стабильны, что затрудняет их применение для анализа высококипящих фенолов.

Так как для хроматографирования полярных соединений рекомендуется использовать неполярные фазы $\left.{ }^{7}\right]$, то в настоящей работе использовались последние.

В нашем распоряжении было силиконовое масло ВКЖ-94, силиконовое масло фирмы «May and Baker», апиезон M и L. Силиконовое масло ВКЖ-94 перед употреблением перегоняли и использовали фракцию $240-260^{\circ} / 2$ м. рт. ст. У исходного масла, а также у остатка перегонки времена удерживания фенолов были слишком велики.

7 ENSV TA Toimetised F-2 65. 
$\overline{\mathrm{V}}_{\mathrm{T}}^{\mathrm{F}}$

C точки зрения селективности разделения близкокипящих одно- и двухатомных фенолов, фракция силиконового масла и другие вышеотмеченные неподвижные фазы мало отличались друг от друга. Наиболее эффективным (по количеству теоретических тарелок) оказался апиезон L. Эта же фаза термически наиболее стабильна, поэтому ее применяли в аналитических колонках. В препаративных колонках использовали также фракцию силиконового масла. Фенолы из-за высокой полярности легко адсорбируются на носителе неподвижной фазы, в результате чего эффективность колонки падает и пики имеют хвосты. Мы исследовали в качестве носителей диатомит $(0,2-0,3 м м)$, обработанный хлористоводородной кислотой, хромосорб W $(0,25-0,32$ м.м), пористое стекло $(0,2-$ $0,5 \boldsymbol{M})\left[{ }^{8}\right]$ и кристаллы хлористого натрия $(0,25-0,36 \boldsymbol{M м})$ [9].

Количество неподвижной фазы составляло: диатомит и хромосорб $15 \%$ от носителя, пористое стекло - 1\%, хлористый натрий - $4 \%$.

Самое низкое хвостообразование было на хромосорбе. Пористое стекло также мало адсорбировало фенолы, но колонки оказались недостаточно эффективными. В дальнейшем в аналитических колонках применяли хромосорб W, в препаративных колонках также диатомит.

При препаративном разделении фенолов пользовались хроматографом УХ-1, колонки имели длину 2 м, диаметр 10 м.. Фенолы разделяли при 180 или $200^{\circ}$. Газом-носителем служили водород или гелий, расход газа составлял $240 \mathrm{~m} / \mathrm{muн}$.

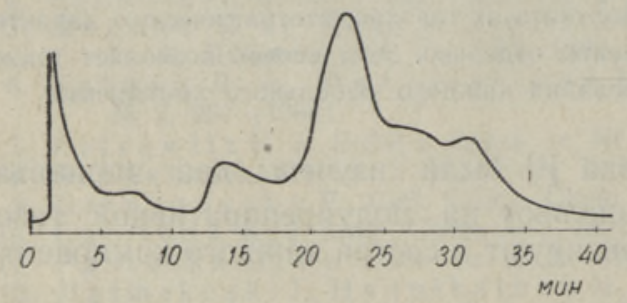

Рис. 1. Хроматограмма фракции 288 $290^{\circ}$ на препаративной колонке. Условия хроматографирования: длина колонки - 2 м; СЖФ - силиконовое масло, $15 \%$ от веса диатомита $(0,165-0,2$ мм) ; температура $-200^{\circ}$; расход водорода - 240 мл/мин; давление 0,45 атм.

Количество разделяемых фенолов составляло до 500 мг. Хроматограмма разделения одной фракции фенолов на препаративной колонке представлена на рис. 1 и ее хроматограмма на аналитической колонке - на рис. 4. Характеристика фракций дана в табл. 1.

Таблица 1

Характеристика некоторых фракций фенолов, выделенных из смолы туннельных печей

\begin{tabular}{|c|c|c|c|c|}
\hline \multirow{2}{*}{$\begin{array}{c}\text { Номер } \\
\text { фракции }\end{array}$} & Температура & кипения, ${ }^{\circ} \mathrm{C}$ & \multirow{2}{*}{$\begin{array}{c}\text { Показатель } \\
\text { преломления } \\
n_{D}^{20}\end{array}$} & \multirow{2}{*}{$\begin{array}{l}\text { Удельный } \\
\text { вес } d_{4}^{20}\end{array}$} \\
\hline & $\begin{array}{l}\text { при нормаль- } \\
\text { ном давлении }\end{array}$ & $\begin{array}{c}\text { в вакууме при } \\
10 \text { мм } \mathrm{Hg}\end{array}$ & & \\
\hline $\begin{array}{l}1 \\
2 \\
3\end{array}$ & $\begin{array}{l}244-247 \\
253-260 \\
288-290\end{array}$ & $\begin{array}{l}116-119 \\
124-129 \\
152-154,5\end{array}$ & $\begin{array}{l}1,5420 \\
1,5308 \\
1,5897\end{array}$ & $\begin{array}{l}1,0123 \\
1,0208 \\
1,0618\end{array}$ \\
\hline
\end{tabular}

Сравнение хроматограмм показывает, что разделение на препаративной колонке несколько хуже, чем на аналитической. Пики компонентов, присутствующих в маленьких количествах, изчезают и их раздельное выделение невозможно.

Фенолы, разделенные на препаративной колонке, конденєировали в конденсаторе, охлажденном твердой углекислотой, и далее дегидроксилировали по [1]. 
При втором варианте 5-15 мкл фенолов разделяли на аналитической колонке, пользуясь двухколоночным хроматографом УХ-1. Разделенные фенолы вместе с газом-носителем - водородом поступали в микрореактор дегидроксилирования, заменивший вторую колонку хроматографа. Микрореакторами служили медные $U$-образные трубки диаметром 4 мм, вставленные в трубчатую печь [10]. Количество катализатора (палладий, $5 \%$ от веса носителя - диатомита или силикагеля) составляло 2 мл. Температура в реакторе была $345^{\circ}$. Пары катализата проходили детекторный блок и конденсатор, конденсаторы менялись после каждого пика на хроматограмме. Фракции катализата анализировали на аргоновом хроматографе «Пай», снабженном ионизационным детектором.

При дегидроксилировании фенолов, кроме ароматических углеводородов, образуется также вода. Попадание воды в ионизационный детектор уменьшает чувствительность последнего [ $\left.{ }^{11}\right]$, поэтому ее необходимо предварительно удалить. Для этой цели на пути газа-носителя между детекторным блоком и конденсатором включали патрон с карбидом кальция $(0,5$ мл), где вода превращалась в ацетилен. Чтобы катализат в патроне не конденсировался, последний был снабжен изоляцией и находился при той же температуре, что и детекторный блок.

Неожиданные трудности встретились при конденсации хроматографических фракций. В первой части настоящей работы при конденсации фенольных фракций выяснилось, что полное выделение фенолов, несмотря на их высокую температуру кипения и малую летучесть, затруднено. Были использованы разные типы стеклянных и металлических конденсаторов. Увеличение поверхности конденсатора и применение для охлаждения вместо твердой углекислоты жидкого воздуха не дало желаемых результатов. Это явление, вероятно, связано с тем, что концентрация высококипящих фенолов в газе очень низка, они уходят в виде тумана. Маленькие размеры конденсатора затрудняют применение электрофильтров для улавливания последнего. Выход конденсата уменьшается еще после дегидроксилирования, так как это связано с увеличением давления паров компонентов. При применении пустых конденсаторов выход катализатов составлял $30-50 \%$ и немного выше после прибавления к ним жидкостей для абсорбции паров конденсата.

Известно, что даже сильно разбавленные пары органических веществ хорошо адсорбируются при низкой температуре на разных сорбентах $\left[{ }^{12}\right]$. В конденсаторе с диатомитом в качестве адсорбента удалось почти полностью сконденсировать катализаты.

Конденсаторы представляли собой стеклянные $U$-образные трубки (внутренний диаметр 1,5-2,0 мм, общая длина 150 мм), охлаждаемые твердой углекислотой. Трубки наполняли 0,03-0,05 мл хорошо высушенным диатомитом $(0,2-0,3$ мм). При прохождении газа через конденсатор образовался кипящий слой, хорошо задерживающий пары катализата. Конденсаторы с выделенными фракциями хранили в сосуде дюара над твердой углекислотой.

Для анализа катализатов использовали ионизационный хроматограф «Пай» со стандартными прямыми колонками длиной 1,2 м. При введении пробы в колонку газовый поток прекращается, что удобно для введения пробы в твердом виде. Так как вес анализируемой пробы не превыщал 0,1 м2, в хроматографическую колонку вводили не все количесто конденсата, адсорбирующегося на диатомите, а только несколько кусочков диатомита.

Метод дегидроксилирования проверяли при анализе нескольких фракций фенолов, выделенных из смолы туннельных печей, характеристика которых представлена в табл. 1. Так как для анализа 

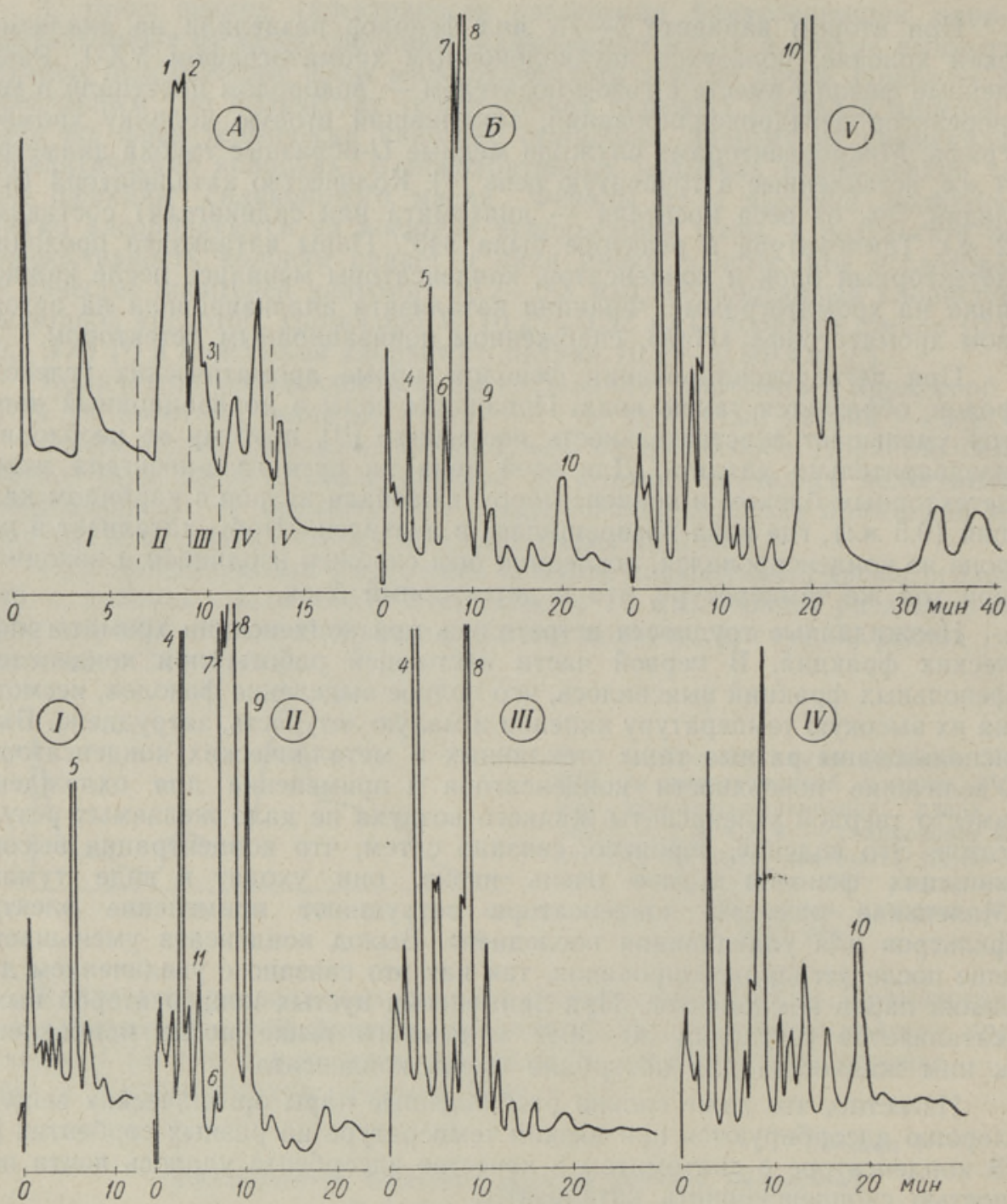

Рис. 2. Анализ фенольной фракции $244-247^{\circ}$. A. Хроматограмма фракцин. Условия хроматографирования: длина колонки - $6 \mu$; СЖФ - апиезон L, $15 \%$ от веса хромосорба W; температура $-200^{\circ}$; расход водорода -60 мл/мин; давление - 1,2 атм. Б. Хроматограммы суммарного катализата и отдельных катализатов (I-IV). Условия хроматографирования: длина колонки 1,2 м; СЖФ - полиэтиленгликоль $4000,15 \%$ от веса диатомита; температура $-100^{\circ}$; расход аргона - 45 мл/мин; давление - 0,35 атм. Обозначения пиков: 1 4-этил-2-метилфенол + 5-этил-2-метилфенол; $2-3$-пропилфенол; 3 - 4-этил-3-метилфенол; 4 - толуол; $5-\mu+n$-кснлол; 6 - $о$-ксилол; $7-\mu$-пропилбензол; 8 - 1-метил-3-этилбензол + 1-метил-4-этилбензол; 9 - 1-метил-2-этилбензол; 10 - индан; 11 - этилбензол.

катализата использовали только часть конденсата, то для получения количественных данных фенолы дегидроксилировали и по методу [1] в один прием. Результаты опытов представлены на рис. 2,3 и 4, где приведены хроматограммы исходных фенолов, суммарных катализатов и отдельных катализатов, полученных по второму варианту дегидроксилирования. Соответствующие участки катализатов и исходных фенолов отме- 


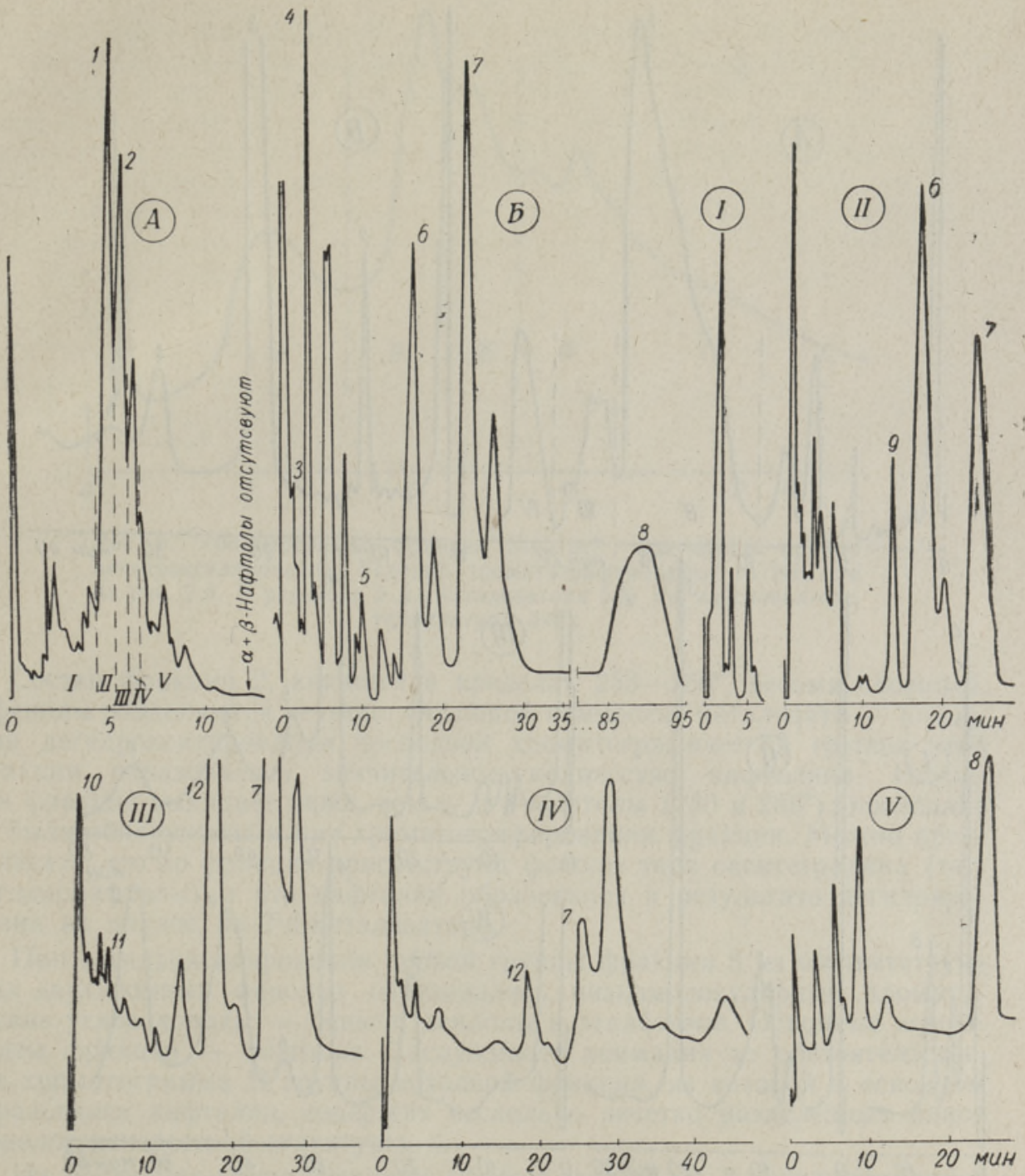

Рис. 3. Анализ фенольной фракции $253-260^{\circ}$. A. Хроматограмма фракции. Условия хроматографирования: длина колонки - 3 м; СЖФ - апиезон $\mathrm{L}, 15 \%$ от веса хромосорба W; температура - $200^{\circ}$; расход водорода - $60 \mathrm{M} / \mathrm{Muн;} \mathrm{дав-}$ ление - 1,0 атм. Б. Хроматограммы суммарного катализата и отдельных катализатов (I-IV). Условия хроматографирования: длина колонки - 1,2 м; СЖФполиэтиленгликоль $4000,15 \%$ от веса диатомита; температура - 100 (I-IV) и $150^{\circ}(\mathrm{V})$; расход аргона $45 \mathrm{мл/мин;} \mathrm{давление} \mathrm{-} 35$ атм. Обозначения пиков: 1 - 4-инданол; 2 - 5-инданол; 3 - бензол; 4-4-толуол; 5-1-метил-4-этилбензол + 1-метил-3-этилбензол; $6-1,4+1,3$-диэтилбензол; 7 - индан; 8 - нафталин; 9 - 1-метил-2-этилбензол; 10 - бензол; 11 - этилбензол; 12 метилэтилбензолы.

чены номерами. По временам удерживания [5] в исходных фенолах было идентифицировано несколько индивидуальных соединений.

На рис. 5 представлена хроматограмма фракции 1, полученная при ее дегидроксилировании. При сравнении ее с хроматограммой рис. $2 A$ выясняется, что вследствие адсорбции на катализаторе пики на хроматограмме ухудшаются. 


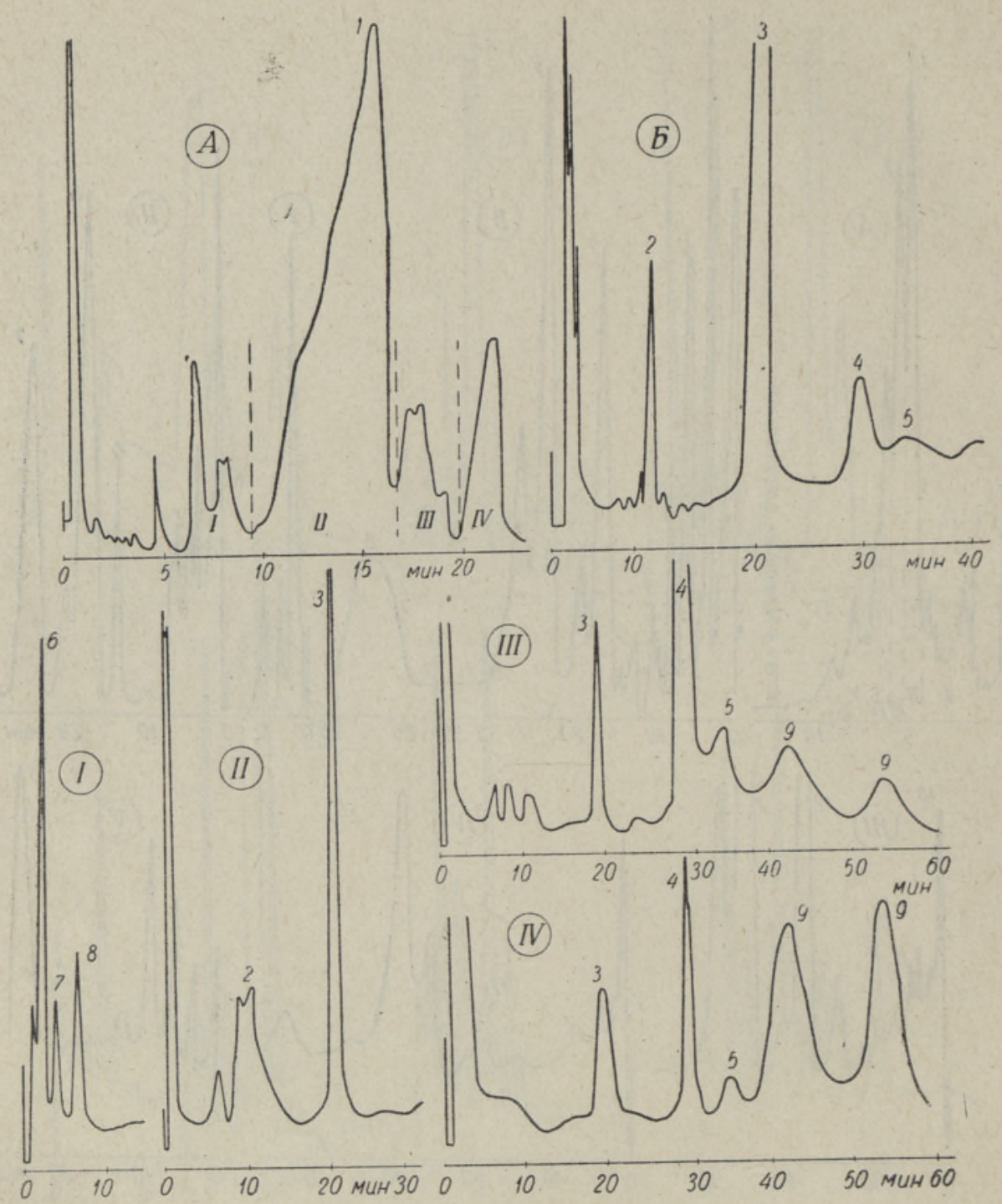

Рис. 4. Анализ фенольной фракции $288-290^{\circ}$. А. Хроматограмма фракции. Условия хроматографирования: длина колонки - 3 , СЖФ - апиезон L, $15 \%$ от веса хромосорба; температура - $200^{\circ}$; расход водорода - $60 \mathrm{M \Omega} /$ мин; давление - 1,0 атм. Б. Хроматограммы суммарного каталивата и отдельных катализатов (I-IV). Условия хроматографирования: длина колонки - 1,2 м; СЖФ - полиэтиленгликоль $4000,15 \%$ от веса диатомита; температура -100 (I) и $150^{\circ}$ (II-IV); расход аргона - 45 мл/мин; давление $-0,35$ атм. Обозначения пиков: $1-\alpha+\beta$-нафтолы; $2-$ тетралин; $3-$ нафталин; $4-\alpha$-метилнафталины; 5 - $\beta$-метилнафталин; 6 - бензол; 7 - толуол; 8 - этилбензол; 9 - диметилнафталины.

Ухудшение хроматограмм в результате адсорбции фенолов на катализаторе было отмечено и ранее [1]. Пики нейтральных кислородных и ароматических соединений при проходе через реактор не ухудшались.

Последовательность выхода ароматических соединений, полученных при дегидроксилировании отдельных хроматографически разделенных групп, остается такой же, как и для суммарного катализата. 


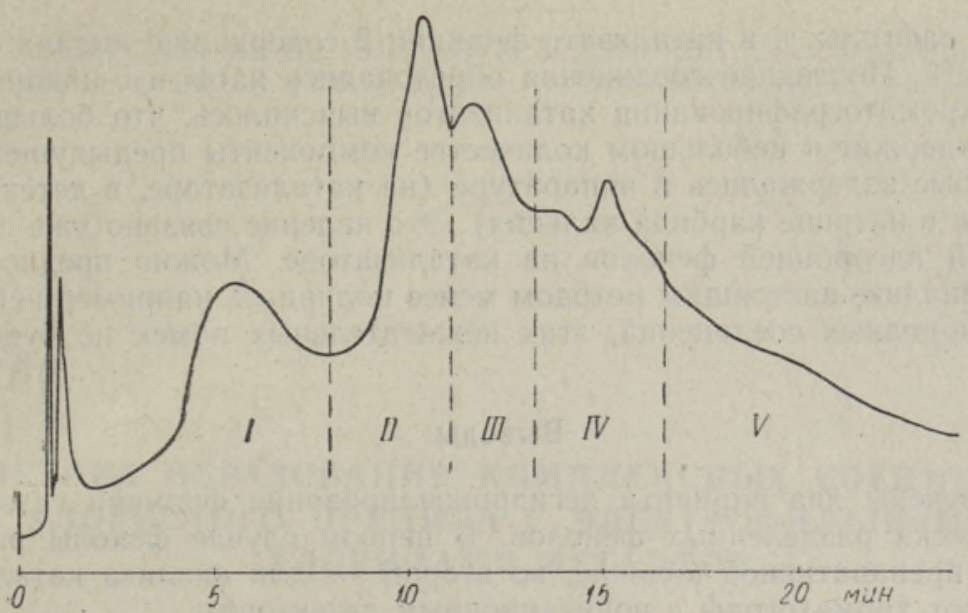

Рис. 5. Хроматограмма фракции $244-247^{\circ}$, полученная при ее дегидроксилированин. Условия хроматографирования те же, что на рис. 2 . В реакторе 2 мл катализатора $5 \% \mathrm{Pd}$ на силикагеле, температура $345^{\circ}$.

Состав фракции 2, кипящей в пределах 253-260, весьма сложный, и фенолы разделяются нечетко. Основной компонент катализата - индан. При дегидроксилировании последней хроматографической группы этой фракции образовалось значительное количество нафталина. Исходная фракция выкипает ниже, чем $\alpha$ - и $\beta$-нафтолы $\left(280\right.$ и $\left.286^{\circ}\right)$; последние не были обнаружены и при хроматографировании фракции. Можно предполагать, что во фракции присутствуют фенолы типа окситетралина (тетрагидронафтолы) и что нафталин образовался в результате дегидрирования их циклов на Pd-катализаторе.

При дегидроксилировании первой группы фракции 3 из соответствующих двухатомных фенолов образовались низкомолекулярные ароматические углеводороды - бензол, ксилолы и этилбензол. Основные компоненты фракции - нафтолы. Заслуживает внимания то обстоятельство, что хроматограмма II группы исходной фракции, из которой в основном образовался нафталин, содержит несколько нечетко разделенных пиков фенолов неизвестной структуры.

Из последних групп фракции образовались 1- и 2-метилнафталины; содержание алкилфенолов во фракции незначительно.

Анализ результатов показывает, что последовательность ароматических углеводородов в катализатах такая же, как и в суммарном катализате. Это, конечно, действительно только в случае применения для разделения фенолов неполярной колонки, в полярной колонке двухатомные фенолы (и соответствующие низкомолекулярные ароматические углеводороды) вышли бы из аппаратуры последними.

Заслуживает внимания образование нафталина из фракции 2 в количестве $16,9 \%$ от катализата. При применении в качестве катализатора $\mathrm{Pd}$-диатомита процессы дегидроциклизации не протекают $\left[{ }^{10}\right]$, нафталин может образоваться только из тетрагидронафтолов. В литературе отсутствуют данные о наличии последних в сланцевых смолах, также неизвестны их физико-химические свойства. Присутствие тетрагидронафтолов в сланцевых смолах можно считать вполне реальным, так как они содержат большое количество бициклических фенолов с близкой структурой. Основными компонентами фракции 3 , анализируемой в настоящей рабо- 
те, были нафтолы, а в катализате фракции 2 содержание индана составляло $22,6 \%$. Последние соединения образовались из 4- и 5-инданола.

При хроматографировании катализатов выяснилось, что большинство из них содержит в небольшом количестве компоненты предыдущей группы, которые задержались в аппаратуре (на катализаторе, в детекторном блоке или в патроне карбида кальция). Это явление связано уже с вышеописанной адсорбцией фенолов на катализаторе. Можно предполагать, что при анализе настоящим методом менее полярных, например нейтральных кислородных соединений, этих нежелательных помех не будет.

\title{
Выводы
}

1. Изучены два варианта дегидроксилирования фракций газохроматографически разделенных фенолов. В первом случае фенолы разделяются на препаративной колонке, во втором - для анализа катализатов используют хроматограф с ионизационным детектором.

2. Данным методом в сланцевой полукоксовой смоле определено присутствие фенолов типа тетрагидронафтола.

\section{ЛИТЕ РАТ У Р А}

1. Клесмент И. Р., Эй зен О. Г., Горючие сланцы, № 5, 30 (1963).

2. J a n a k J., Komers S., Coll. Czech. Chem. Commun., 24, 1960 (1959).

3. B r o ok s V. T., Chem. and Ind. (London), No. 42, 1317 (1959).

4. M a he r T. P., J. Chromatog., 10, No. 3, 324 (1963).

5. Fitz ge r a ld J. S., Australian J. Appl. sci., 10, 306 (1959).

6. Porcaro P. J., Johnston V. D., Anal. Chem., 34, No. 9, 1071 (1962).

7. C a s on J., Mille r W. T., J. Org. Čhem., 23. No. 11, 1814 (1959).

8. Кестнер А. И., Ж. физ. хим., 37, № 3, 707 (1963).

9. Nels on J., Milun A., Chem. and Ind., No. 23, 663 (1960).

10. Клесмент И. Р., Р анг С. А., Э й зе н О. Г., Нефтехимия, 3, № 6, 864 (1963).

11. S wo bod a P. A. T., Chem. and Ind. (London), No. 41, 1262 (1960).

12. Brenner N., Ettre L. S., Anal. Chem., 3, No. 11, 1815 (1959).

\author{
Институт химии \\ Академии наук Эстонской ССР \\ Поступила в редакцию \\ 30/IV 1964
}

\section{KLESMENT, E. LAGEDA}

\section{FENOOLIDE IDENTIFITSEERIMINE GAASIKROMATOGRAAFILISTES FRAKTSIOONIDES KATALUUTILISE DEHODROKSULEERIMISEGA}

Gaasikromatograafilises kolonnis lahutatud fenoolid lasti läbi dehüdroksüleerimisreaktori, tekkinud aromaatsed süsivesinikud kondenseeriti eraldi. Esitatakse kaks gaasikromatograafia-mikroreaktortehnika varianti.

Dehüdroksüleerimismeetodit kontrolliti mōningate pōlévkivifenoolifraktsioonide (keemistemperatuur $240-300^{\circ} \mathrm{C}$ ) analüüsimisega. Nendes fraktsioonides leiti tetrahüdronaftooli ja indanooli tüüpi fenoole.

\section{KLESMENT, E. LAGEDA}

\section{IDENTIFICATION OF PHENOLIC COMPOUNDS IN GASCHROMATOGRAPHIC FRACTIONS BY MEANS OF CATALYTIC DEHYDROXYLATION}

Phenols separated in the chromatographic strips were run through the dehydroxylation reactor, and the obtained aromatic compounds were condensed separately.

Two variants of the gaschromatographic microreactor technique are presented. The method of the dehydroxylation was checked up with some fractions of shale oil phenolic compounds (boiling temperature $240-300^{\circ}$ ). Phenols of the tetrahydronaphthol and indanole type were found in these fractions. 